\title{
Tau mis-splicing in the pathogenesis of neurodegenerative disorders
}

\author{
Sun Ah Park ${ }^{1, *}$, Sang Il Ahn ${ }^{1}$ \& Jean-Marc Gallo ${ }^{2}$ \\ ${ }^{1}$ Department of Neurology, Soonchunhyang University Bucheon Hospital, Bucheon 14584, Korea, ${ }^{2}$ Department of Basic and Clinical \\ Neuroscience, Maurice Wohl Clinical Neuroscience Institute, Institute of Psychiatry, Psychology and Neuroscience, King's College London, \\ London SE5 9NU, UK
}

Tau proteins, which stabilize the structure and regulate the dynamics of microtubules, also play important roles in axonal transport and signal transduction. Tau proteins are missorted, aggregated, and found as tau inclusions under many pathological conditions associated with neurodegenerative disorders, which are collectively known as tauopathies. In the adult human brain, tau protein can be expressed in six isoforms due to alternative splicing. The aberrant splicing of tau pre-mRNA has been consistently identified in a variety of tauopathies but is not restricted to these types of disorders as it is also present in patients with non-tau proteinopathies and RNAopathies. Tau mis-splicing results in isoform-specific impairments in normal physiological function and enhanced recruitment of excessive tau isoforms into the pathological process. A variety of factors are involved in the complex set of mechanisms underlying tau mis-splicing, but variation in the cis-element, methylation of the MAPT gene, genetic polymorphisms, the quantity and activity of spliceosomal proteins, and the patency of other RNA-binding proteins, are related to aberrant splicing. Currently, there is a lack of appropriate therapeutic strategies aimed at correcting the tau mis-splicing process in patients with neurodegenerative disorders. Thus, a more comprehensive understanding of the relationship between tau mis-splicing and neurodegenerative disorders will aid in the development of efficient therapeutic strategies for patients with a tauopathy or other, related neurodegenerative disorders. [BMB Reports 2016; 49(8): 405-413]

\section{INTRODUCTION}

Tau is a microtubule-associated protein that is abundant in the

${ }^{*}$ Corresponding author. Tel: +82-32-621-5221; Fax: +82-32-6215014; E-mail: sapark@schmc.ac.kr

http://dx.doi.org/10.5483/BMBRep.2016.49.8.084

Received 16 May 2016

Keywords: Isoform, Mechanism, Splicing, Tau, Tauopathy brain, particularly in neurons. This protein is primarily located in axons, where it binds to microtubules to stabilize these structures and support axonal transport (1). In pathological conditions, the tau protein commonly aggregates to form neurofibrillary tangles - as seen in Alzheimer's disease (AD) pick bodies in Pick's disease (PiD), and tau inclusions, such as in corticobasal degeneration (CBD), progressive supranuclear palsy (PSP), argyrophilic grain disease (AGD), frontotemporal dementia (FTD), and myotonic dystrophy type 1 (DM1) (2-6). These disorders are collectively known as tauopathies due to their distinct tau pathologies, but the most advanced understanding of the mechanisms underlying tau pathology pertains to AD.

Post-translational modifications, such as hyperphosphorylation, acetylation, and truncation result in tau proteins losing their binding affinity with the microtubule, which, in turn, allows them to become self-aggregated (7). Subsequently, the instability of the neuronal cytoskeleton due to a lack of bound tau proteins in conjunction with the toxicity of tau oligomers leads to neurodegeneration (8). Furthermore, this process can spread into adjacent or connected neurons via synaptic connections (9), which explains the characteristic progressive pattern of tau pathologies (6). Therefore, a majority of therapeutic strategies aimed at treating tauopathies target reductions in tau toxicity at the protein level via decreased phosphorylation, enhanced clearance, and inhibition of the aggregation of tau proteins (10).

In contrast, therapies aimed at altering tau transcription are less common. Based on the alternative splicing of exons 2, 3, and/or 10 in the MAPT gene, tau proteins may be present in six isoforms in the human brain (11). Furthermore, the appearance of tau isoforms differs according to age and brain region (11), which is important with respect to normal brain development and physiological function. Genetic studies investigating the mis-splicing of tau pre-mRNA have shown that it plays a role in the pathogenesis of PSP, CBD, PiD, AGD, and FTD $(12,13)$ but progress in terms of understanding this process remains limited and further investigation is required. Thus, the present paper aimed to review recent knowledge regarding tau RNA splicing and examine the role of this process in neurodegenerative disorders.

ISSN: 1976-670X (electronic edition)

Copyright (c) 2016 by the The Korean Society for Biochemistry and Molecular Biology

(c) This is an open-access article distributed under the terms of the Creative Commons Attribution Non-Commercial License (http://creativecommons.org/licenses/by-nc/4.0) which permits unrestricted non-commercial use, distribution, and reproduction in any medium, provided the original work is properly cited. 


\section{TAU ALTERNATIVE SPLICING AND ISOFORM-SPECIFIC FUNCTIONS}

The tau protein is encoded from the MAPT gene, which is located at chromosome 17q21 (14). There are 16 exons in the MAPT gene and exons 2, 3, 4A, 6, 8, and 10 can be alternatively spliced (11). Exons 4A, 6, and 8 are not transcribed in the brain; thus, six isoforms are produced in the brain through different combinations of the splicing of exons 2, 3, and/or 10 (Fig. 1). Exons 2 and 3 are translated into the $\mathrm{N} 1$ and $\mathrm{N} 2$ aspects of the $\mathrm{N}$-terminal projection domain, respectively (15), which play important roles in signal transduction and membrane interactions $(16,17)$. The encoding region of exon 10 is the second aspect of the C-terminal microtubule-binding repeat domain, $\mathrm{R} 2$, and the resulting tau proteins become either $3 R$ or $4 R$ tau, which differ in the number of repeats depending on the splicing of exon 10 (15). Because the microtubule-binding repeat domain of tau is its binding site to a microtubule (18), it is essential for the ability of the tau protein to maintain the stability, and regulate the dynamics, of microtubules (19), as well as to support axonal transport (1).

The difference in the number of repeats determines the strength of the binding of the tau protein to microtubules; $4 R$ tau binds to microtubules more tightly than $3 R$ tau, which is better for stabilizing the microtubule (20), but the extra repeat makes it more likely that $4 R$ tau will aggregate $(21,22)$. Additionally, the dynamics of both retrograde and anterograde axonal transport are higher for the $3 R$ isoform than the $4 R$ isoform (23). The tau isoform-dependent differences in microtubule-binding capacity and axonal transport may explain the benefits of changes in tau isoforms during various developmental stages; $3 \mathrm{R}$ tau is the main isoform present in the fetal stage, during which the dynamic nature of the axon is an important requirement for synaptogenesis and establishing neural pathways (24). On the other hand, the overall ratio of

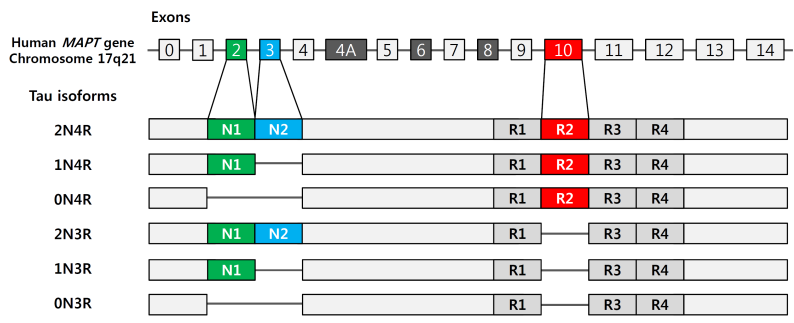

Fig. 1. Tau protein isoforms in the human brain. Six tau isoforms are present in the human brain through different combinations of the splicing of exons 2, 3, and/or 10. The aspects of the $\mathrm{N}$-terminal projection domain, N1 (green) and N2 (blue), are produced from exons 2 and 3, respectively. Exon 10 encodes the second aspect of the microtubule-binding repeat domain, R2 (red). Depending on the presence of the R2 domain, tau proteins become either $3 \mathrm{R}$ or $4 \mathrm{R}$ tau.
$3 R$ to $4 R$ in the mature human brain is maintained at $1: 1$ (11) even though the relative amounts of these isoforms vary according to brain region and cell type. For example, granule cells in the hippocampus only express the $3 R$ tau isoform (24, 25) and this difference is thought to provide the cells in this region with a particular resistance or susceptibility to specified tauopathies (25-27).

Alternative splicing of the tau protein can also occur at exons 2 and 3 to produce the $0 \mathrm{~N}, 1 \mathrm{~N}$, and $2 \mathrm{~N}$ tau isoforms, which differ in the number of amino-terminal ( $\mathrm{N}$-terminal) inserts. Interestingly, exon 3 is spliced only when exon 2 is present $(11,13)$; thus, the $1 \mathrm{~N}$ isoform is produced from a combination of exon $2+$ /exon 3 - but not from exon2-/exon $3+$. The relative amounts of the $\mathrm{N}$-terminal isoforms are regulated in the human adult brain such that the $2 \mathrm{~N}$ isoform is the least expressed while the $1 \mathrm{~N}$ isoform is the most abundant (28). This difference does not seem to have a direct impact on microtubule assembly (15) but it was recently suggested that the $\mathrm{N}$-terminal projection domain plays an active role during the regulation of microtubule stabilization (29). When the tau protein is truncated at $\mathrm{Gln} 124$ in the $\mathrm{N}$-terminal due to the deletion of repeat inserts, there is an increase in its binding affinity to the microtubule compared to the full-length tau protein (29).

The $1 \mathrm{~N}$ isoform, which contains an $\mathrm{N} 1$ insert from exon 2, enhances the self-aggregating tendency of the tau protein (30) while the N2 insert from exon 3, which has an additional $\mathrm{N}$-terminal domain, attenuates the aggregation-promoting effects of the $\mathrm{N} 1$ insert (30). The $\mathrm{N}$-terminal repeat inserts interact with various molecules in the human brain that are involved in synaptic signaling, energy metabolism, and cytoskeletal function. When the interaction proteins were analyzed according to the individual $\mathrm{N}$-terminal inserts using bioinformatics with biological process enrichment, the N2 insert was shown to interact with several molecules related to neurodegenerative disorders including 14-3-3 zeta, ApoA1, ApoE, synaptotagmin, and syntaxin 1B (31). These findings suggest that the N0, N1, and N2 isoforms behave differently under different physiological and pathological conditions; thus, it is possible that the mis-splicing of exons 2 and 3 contributes to various tauopathies. However, direct evidence demonstrating this relationship is lacking and more intensive studies are needed to further elucidate this issue.

\section{MECHANISMS UNDERLYING THE SPLICING REGULATION OF THE TAU TRANSCRIPT}

The assembly of the spliceosome, which is a multi-protein complex to the cis-acting pre-mRNA sequence, is an essential step in the splicing process (32). The cis-acting element is a short and diverse sequence that can be located in either the exon or intron; its influence differs depending on location and sequence. Based on their effects on splicing, cis-elements are classified as splicing enhancers, silencers, or modulators (32). 
Table 1. Factors regulating the splicing of exon 10 of MAPT pre-mRNA

\begin{tabular}{|c|c|c|}
\hline cis-elements & Sequence & $\begin{array}{l}\text { Effect on } \\
\text { E10 }\end{array}$ \\
\hline SC35-like enhancer & E10, TGCAGATA & Inclusion \\
\hline $\begin{array}{l}\text { Polypurine enhancer } \\
\text { (PPE) }\end{array}$ & E10, AAGAAGCTG & Inclusion \\
\hline $\begin{array}{l}\text { A/C-rich enhancer } \\
\text { (ACE) }\end{array}$ & E10, AGCAACGTCCAGTCC & Inclusion \\
\hline $\begin{array}{l}\text { Exonic splicing } \\
\text { silencer (ESS) }\end{array}$ & $\begin{array}{l}\text { E10, } \\
\text { TCAAAGGATAATATCAAA }\end{array}$ & Exclusion \\
\hline $\begin{array}{l}\text { Exonic splicing } \\
\text { enhancer (ESE) }\end{array}$ & $\begin{array}{l}\text { E10, } \\
\text { CACGTCCCGGGAGGCGGC }\end{array}$ & Inclusion \\
\hline $\begin{array}{l}\text { Intronic splicing } \\
\text { silencer (ISS) }\end{array}$ & I10, tcacacgt & Exclusion \\
\hline $\begin{array}{l}\text { Intronic splicing } \\
\text { modulator (ISM) }\end{array}$ & 110, cccatgcg & \\
\hline SR proteins & & $\begin{array}{l}\text { Effect on } \\
\text { E10 }\end{array}$ \\
\hline $\begin{array}{l}\text { SRSF1: ASF, SF2, } \\
\text { SRp30a }\end{array}$ & & Inclusion \\
\hline $\begin{array}{l}\text { SRSF2: SC35, } \\
\text { PR264, SRp30b }\end{array}$ & & Inclusion \\
\hline SRSF3: SRp20 & & Exclusion \\
\hline SRSF4: SRp75 & & Exclusion \\
\hline SRSF6: SRp55, B52 & & Exclusion \\
\hline SRSF7: SRSF3 9G8 & & Exclusion \\
\hline SRSF9: SRp30c & & Inclusion \\
\hline SRSF11: P54, SRp54 & & Exclusion \\
\hline $\begin{array}{l}\text { Other RNA binding } \\
\text { proteins }\end{array}$ & & $\begin{array}{l}\text { Effect on } \\
\text { E10 }\end{array}$ \\
\hline RBM4 & & Inclusion \\
\hline $\operatorname{Tra} 2 \beta$ & & Inclusion \\
\hline DDX5 (RNA helicase p68) & & Inclusion \\
\hline hnRNPE2 and hnRNPE3 & & Inclusion \\
\hline hnRNPG & & Exclusion \\
\hline SWAP & & Exclusion \\
\hline CELF2 & & Exclusion \\
\hline CELF3, TNRC4 & & Inclusion \\
\hline PTBP2 & & Inclusion \\
\hline PSF & & Exclusion \\
\hline miRNAs & Target SF & $\begin{array}{l}\text { Effect on } \\
\text { E10 }\end{array}$ \\
\hline miR-9 & PTBP1 & Exclusion \\
\hline miR-124 & PTBP1 & Exclusion \\
\hline miR-132 & PTBP2 & Exclusion \\
\hline Kinases & Target SF & $\begin{array}{l}\text { Effect on } \\
\text { E10 }\end{array}$ \\
\hline CLK2 & & Exclusion \\
\hline PKA & 9G8 & Inclusion \\
\hline
\end{tabular}

Table 1. Continued

\begin{tabular}{lll}
\hline \multicolumn{1}{c}{ Kinases } & Target SF & $\begin{array}{c}\text { Effect on } \\
\text { E10 }\end{array}$ \\
\hline PKA & SC35 & Inclusion \\
DYRK1 & SC35 & Exclusion \\
DYRK1 & 9G8 & $*$ Inclusion \\
DYRK1 & ASF & Exclusion \\
DYRK1 & SRP55 & Exclusion \\
GSK-3 3 & SC35 & Exclusion \\
\hline
\end{tabular}

DYRK1, dual-specificity tyrosine-phosphorylated and regulated kinase $1 \mathrm{~A}$; E, exon; I, intron; PTBP2, polypyrimidine tract-binding protein 2; RBM4, RNA-biding motif protein 4; SF, splicing factors; PKA, cyclic AMP-dependent protein kinase; PSF, polypyrimidine tract binding protein associated splicing factor; SWAP, suppressor of white apricot protein.

*Variable depending on cell type (45).

Summarized from the literature $(12,13,33-48)$.

The MAPT gene mutations that are close to, or within, the cis-acting elements result in FTD with Parkinsonism linked to chromosome 17 (FTDP-17) and other tauopathies associated with mis-splicing (12). Many serine- and arginine-rich (SR) proteins possess a specific affinity for the cis-element of the MAPT gene and regulate the splicing of exon 10 (33) (Table 1). In addition to these proteins, several non-SR proteins also play a role in the splicing of exon 10. For example, RNA-binding motif protein 4 (RBM4) (34), Tra2 $\beta$ (35), RNA helicase p68 (36), heterogeneous nuclear (hn) RNP E2 and E3 $(37,38)$, and CUG-binding protein (CELF) $(39,40)$ are known to be involved. The variants that depend on the cis-element and splicing factors likely act cooperatively to determine the efficacy and direction of the splicing of exon 10 in the MAPT gene.

The regulation of alternative splicing processes is further complicated by variables arising from the altered expression and activity of splicing factors following modifications at the transcriptional, post-transcriptional, and post-translational levels. miRNA-132 is known to regulate the splicing of exon 10 via the inhibition of the expression of the PTBP2 protein, which is a splicing factor (41). Additionally, various kinases, including cyclic AMP-dependent protein kinase (PKA) $(42,43)$, dualspecificity tyrosine-phosphorylated and regulated kinase $1 \mathrm{~A}$ (DYRK1) (44-47), and GSK-3 $\beta$ (48), regulate the activities of splicing proteins via phosphorylation and, thereby, exon 10 splicing. This issue has been well described in a recent review article (33). From an epigenetic point of view, the regulation of splicing by DNA methylation may also be involved in this process (26). The speed of RNA polymerase II during the elongation and reposition of splicing factors to alternative exons by heterochromatin protein 1 (HP1) is controlled by DNA methylation (49). Considering that a $\mathrm{CpG}$ island is present in exon 9, it is the possible that DNA methylation plays a role in regulating the alternative splicing of the MAPT 
gene (26) but there is a lack of studies investigating this issue.

Relative to the processes associated with the splicing of exon 10 , the regulatory mechanisms underlying the alternative splicing of exons 2 and 3 are less clear. Several spliceosomal proteins involved in exon 10 splicing also regulate exon 3 splicing. For example, SRSF1, SRSF2, SRSF3, SRSF9, SWAP, Tra2 $\beta$, and Nova 1 decrease the inclusion of exon 3 while SRSF4 and SFSF6 enhance its inclusion (13). According to the linkage disequilibrium of nucleotide polymorphisms, the MAPT gene has two major haplotypes, $\mathrm{H} 1$ and $\mathrm{H} 2$, and the alternative splicing processes exhibit different patterns depending on haplotype. The $\mathrm{H} 2$ haplotype of the MAPT gene tends to include the exon $3(27,50)$. Furthermore, the transcriptional efficacy and DNA methylation patterns of the $\mathrm{H} 1$ and $\mathrm{H} 2$ haplotypes, which are described in detail below, also differ. In conjunction, the differential roles of the haplotypes are thought to contribute to haplotype-dependent tauopathies $(51,52)$.

\section{TAU MIS-SPLICING AND NEURODEGENERATIVE DISORDERS}

\section{Genetic mutations in the MAPT gene}

Genetic mutations in the MAPT gene can result in PSP, CBD, PiD, and FTDP-17. These pathogenic mutations of the MAPT gene are primarily located within exons 9-13 (Fig. 2) but are not limited to point missense and deletional mutations in exons. In fact, silent, and even intronic, mutations can induce a tauopathy (12). The boundary of exon10/intron 10 includes an RNA sequence that forms a stem-loop due to selfcomplementary bindings at the stem and this region is a hot spot for MAPT gene mutations. Most of the pathogenic intronic mutations are clustered in the stem-loop where mutations induce the mis-splicing of exon 10 by decreasing

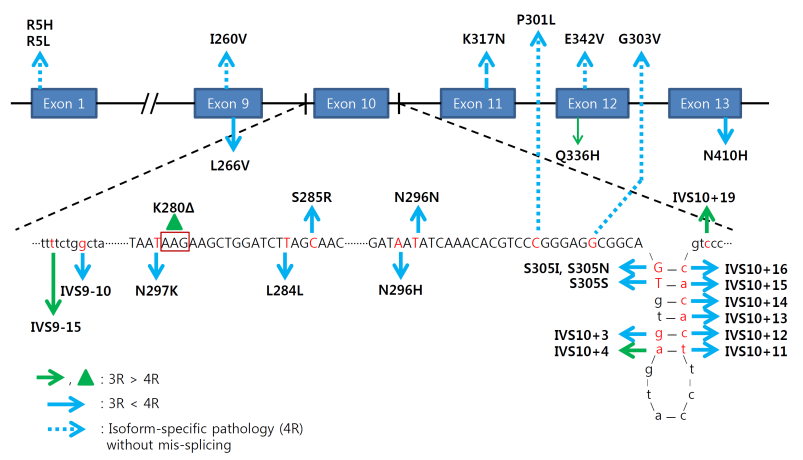

Fig. 2. Causative MAPT gene mutations associated with tauopathies. The differential impacts of the causative MAPT gene mutations on tau-isoform specific pathologies can be demonstrated in three ways: 1) tau mis-splicing that increases either $3 R$ tau (green line or arrowhead) or 2) 4R tau isoforms (blue line) and 3) $4 \mathrm{R}$ tau isoform-distinct pathologies without mis-splicing (blue dotted line). stem-loop stability, which in turn increases the inclusion of exon 10. Subsequently, the altered RNA structure enhances the accessibility of the spliceosome to this region and results in mis-splicing $(36,53)$. Ultimately, these intronic mutations clinically manifest as FTD in most cases, via increases in either the $3 R$ or $4 R$ tau isoform; IVS9-10 G $>$ T, IVS10+3 G $>A$, IVS10+11 T $>$ C, IVS10+12 C $>$ T, IVS10+13 A $>$ G, IVS10+14 C > T, IVS10+15 A > C, and IVS10+16 C > T tend to increase 4R tau (53-58) while IVS9-15 $\mathrm{T}>\mathrm{C}$, IVS10 $+4 \mathrm{~A}>\mathrm{C}$, and IVS10 $+19 \mathrm{C}>\mathrm{G}$ inhibit the inclusion of exon 10 and increase $3 R$ tau $(59,60)$. L284L (CTT to CTC), $\mathrm{N} 296 \mathrm{~N}$ (AAT to AAC), and S305S (AGT to AGC) are silent point mutations that result in tauopathy, FTD, or PSP (61-63). Their location is close to the exon 10/intron 10 interface and increases the $4 \mathrm{R}$ tau isoform by enhancing the inclusion of exon 10. The mechanisms underlying the neurodegeneration caused by perturbations of the $3 R-4 R$ tau balance remain elusive but the isoform-dependent differences in the propensity for aggregation are thought to behave pathologically when the 3R:4R balance is disordered (64).

Changes in the tau protein sequence due to exonic missense and deletion mutations do not always cause alterations in the ratio of the $3 R$ and $4 R$ tau isoforms. Instead, amino acid substitutions alter the tau structure into pathological forms (65). Interestingly, despite the fact that exon 10 is not mis-spliced, distinctive isoform-specific pathologies have been noted. R5H (66), R5L (67), I260V (68), P301L (57), G303V (69), and K317N (70) result in an increased propensity for aggregation and filament formation of $4 R$ tau proteins without altering the $3 R: 4 R$ tau ratio. The dominance of $4 R$ tau isoform-specific pathologies in the absence of mis-splicing suggests that the $4 \mathrm{R}$ tau isoform is susceptible to becoming pathological following a mutation of the MAPT gene.

It is rare that pathogenic MAPT gene mutations will lead to the mis-splicing of exons 2 and 3. The E342V mutation in exon 12 causes an increased splicing of exon 10, but the reduced inclusion of exons 2 and 3 (71), and the tau inclusions in the R5L mutation of exon 1 , primarily consist of $4 R$ tau with either no insert or the N1 insert (0N4R or $1 N 4 R$ ) (67). The possible role of an altered number of $\mathrm{N}$-terminal inserts in tauopathies can be considered based on the biological effects of $\mathrm{N}$-terminal inserts in modifying tau aggregation and signaling pathways $(16,17,30,31)$. However, further studies are needed to clarify this issue.

\section{Without genetic mutations in the MAPT gene}

Isoform-specific tau pathologies are also observed in the absence of MAPT gene mutations in sporadic cases of PSP, CBD, PiD, AGD (4R tau), PiB (3R tau), and FTD (mixture of 3R and/or $4 R$ tau). Overt tau mis-splicing can occur in these sporadic cases (72) and it has been suggested that the preference of haplotype for specified splicing is the mechanism underlying the alterations in alternative splicing (12). The $\mathrm{H} 1$ haplotype, particularly the $\mathrm{H} 1 \mathrm{c}$ sub-haplotype, is 
thought to increase the risk of PSP and CBD by increasing exon 10 splicing (73-76). However, a recent study that included a large sample size of brains found opposite results for the $\mathrm{H} 1$ haplotype but a protective influence of the $\mathrm{H} 2$ haplotype against PSP, CBD, and PD via increases in exon 3 (27), as has been previously suggested (50). Various combinations of haplotype-dependent genetic variations are known to modulate DNA methylation (77), transcription, and mRNA splicing $(75,78)$. Thus, the complicated interactions of these factors are thought to cooperatively determine the direction of tau exon splicing.

Differences in the expression and activity of spliceosomal proteins result in aberrant splicing and contribute to the manifestation of a tauopathy. In PSP patients, increases in SRSF2 and Tra2 $\beta$ in the locus coeruleus are associated with increases in the $4 \mathrm{R}$ tau isoform (79). And the decreases of miRNA-132 thereby increase of PTBP2 was shown to enhance $4 R$ tau pathology in the PSP brain (41). The pathogenic role of tau mis-splicing in $\mathrm{AD}$ is controversial and has been previously reviewed (12), but recent reports have raised the possibility that its contribution to AD is due to increased DYRK2 activity in the brain, which continuously increases $3 R$ tau expression and tau pathology (44).

Recent, accumulating evidence suggests the there is a discriminative relationship between tau isoforms and neurodegenerative disorders, which means that certain tau isoforms are more vulnerable to specific pathogenic factors and explains why there are isoform-specific pathologies and regional selectivity in tauopathies $(27,80)$. The relative ratio of tau isoforms varies across cell types and brain regions $(27,80)$ and specified cells and/or regions that contain greater amounts of specified tau isoforms tend to be more easily affected by corresponding disorders $(7,81)$. For example, the quantity of the $4 \mathrm{R}$ tau isoform is higher in the globus pallidum, which may explain why this region is particularly affected by the pathological processes of PSP (81). Likewise, granule cells in the hippocampus exclusively express $3 R$ tau isoforms and the $3 R$ tau-positive pick body is most abundant in PiD patients (25).

Tau mRNA mis-splicing may develop as a co-phenomenon of widespread RNA dysregulation during neurodegenerative processes. As a prime example, 4R tau aggregates have been identified in the striatum and cortex of Huntington's disease (HD) patients (82) while 0N3R tau inclusions are found in DM1 patients $(83,84)$. DM1 and HD are caused by CTG repeats in the DMPK gene (85) and CAG repeats in the HTT gene (86), respectively. In these disorders, tau mRNA mis-splicing is due to impairments in normal alternative splicing that occur subsequent to the sequestration of splicing factors by the abnormally expanded CUG transcripts $(82,87)$. Tau mis-splicing in conjunction with isoform-specific tau pathologies is thought to induce pathogenic cognitive deficits and behavioral changes $(82,84)$. The toxic aggregates of fused in sarcoma (FUS) and TAR DNA-binding protein (TDP-43) in the cytoplasm are observed in patients with amyotrophic lateral sclerosis (ALS) and FTD $(88,89)$. Furthermore, there are mutations in the corresponding genes, FUS and TARDBP, respectively, in familial ALS and FTD (90, 91), which demonstrates the pathogenic roles of FUS and TDP-43 in neurodegenerative disorders. FUS and TDP-43 are nuclear proteins involved in RNA processes such as transcription and the splicing of multiple genes $(92,93)$. In pathological conditions, the inclusion of FUS and TDP-43 as RNA processing proteins results in impaired physiological processes. The altered splicing of exons 3 and 10 in tau pre-mRNA has been observed in FUS-related proteinopathies (94) and it is thought that decreases in the propensity of FUS to directly bind to tau pre-mRNA alters the regulation of the splicing of exons 3 and 10 (94). In contrast, the TDP-43 proteinopathy does not impair tau pre-mRNA alternative splicing (95) despite the extensive RNA mis-processing exerted by the aggregation of TDP-43 proteins, which hinders its normal function as an RNA binding protein (96). Thus, the perturbation of tau pre-mRNA processing by neurodegenerative disorders is determined by the types of proteinopathies and RNAopathies. Future investigations will provide a clearer understanding of the relationship between tau mis-splicing and individual neurodegenerative disorders.

\section{CONCLUSIONS}

The pathogenic contributions of tau mis-splicing are likely highly correlated with the manifestation of neurodegenerative disorders via tauopathies as well as non-tau proteinopathies. This type of mis-splicing leads to an imbalance of tau isoforms that impairs isoform-specific, normal physiological function and enhances vulnerability to pathological processes. Current understanding of the relationship between tau mis-splicing and neurodegenerative disorders is originated from cases of MAPT gene mutations, which widened existing knowledge about the mechanisms underlying tau splicing. Several trials corrected exon 10 mis-splicing in MAPT gene mutations using small molecules (97), modified antisense oligonucleotides (98), or spliceosome-mediated RNA trans-splicing (99) but none of these studies progressed to clinical trials.

A variety of complex factors are involved in the regulation of the alternative splicing of tau. Differences in the integrity of the cis-element, methylation of the MAPT gene, genetic polymorphisms, quantity and activity of spliceosomal proteins, and patency of other RNA binding proteins appear to cooperatively impact alternative tau splicing. In sporadic cases of tauopathy that present with tau-isoform specific pathologies, these variables operate together to influence tau mis-splicing; thus, therapeutic strategies should be much more delicately designed. Current understanding of tau mis-splicing remains limited, especially in terms of its pathological role in non-tau proteinopathies, RNAopathies, and sporadic cases. Further studies should be performed to develop efficient therapeutic strategies for the treatment of these disorders. 


\section{ACKNOWLEDGEMENTS}

This research was supported by a grant of the Korea Health Technology R\&D Project through the Korea Health Industry Development Institute (KHIDI), funded by the Ministry of Health \& Welfare, Republic of Korea (HI14C1943).

\section{REFERENCES}

1. Dixit R, Ross JL, Goldman YE and Holzbaur EL (2008) Differential regulation of dynein and kinesin motor proteins by tau. Science 319, 1086-1089

2. Munoz DG and Ferrer I (2008) Neuropathology of hereditary forms of frontotemporal dementia and parkinsonism. Handb Clin Neurol 89, 393-414

3. Togo T, Sahara N, Yen SH et al (2002) Argyrophilic grain disease is a sporadic 4-repeat tauopathy. J Neuropathol Exp Neurol 61, 547-556

4. Arai T, Ikeda $\mathrm{K}$, Akiyama $\mathrm{H}$ et al (2001) Distinct isoforms of tau aggregated in neurons and glial cells in brains of patients with Pick's disease, corticobasal degeneration and progressive supranuclear palsy. Acta Neuropathol 101, 167-173

5. Sergeant N, Sablonniere B, Schraen-Maschke S et al (2001) Dysregulation of human brain microtubuleassociated tau mRNA maturation in myotonic dystrophy type 1. Hum Mol Genet 10, 2143-2155

6. Braak H and Braak E (1991) Neuropathological stageing of Alzheimer-related changes. Acta Neuropathol 82, 239259

7. Wang Y and Mandelkow E (2016) Tau in physiology and pathology. Nat Rev Neurosci 17, 22-35

8. Ballatore C, Lee VM and Trojanowski JQ (2007) Tau-mediated neurodegeneration in Alzheimer's disease and related disorders. Nat Rev Neurosci 8, 663-672

9. Sanders DW, Kaufman SK, DeVos SL et al (2014) Distinct tau prion strains propagate in cells and mice and define different tauopathies. Neuron 82, 1271-1288

10. Brunden KR, Trojanowski JQ and Lee VM (2009) Advances in tau-focused drug discovery for Alzheimer's disease and related tauopathies. Nat Rev Drug Discov 8, 783-793

11. Goedert M, Spillantini MG, Jakes R, Rutherford D and Crowther RA (1989) Multiple isoforms of human microtubule-associated protein tau: sequences and localization in neurofibrillary tangles of Alzheimer's disease. Neuron 3, 519-526

12. Niblock M and Gallo JM (2012) Tau alternative splicing in familial and sporadic tauopathies. Biochem Soc Trans 40, 677-680

13. Andreadis A (2005) Tau gene alternative splicing: expression patterns, regulation and modulation of function in normal brain and neurodegenerative diseases. Biochim Biophys Acta 1739, 91-103

14. Neve RL, Harris P, Kosik KS, Kurnit DM, Donlon TA (1986) Identification of cDNA clones for the human microtubuleassociated protein tau and chromosomal localization of the genes for tau and microtubuleassociated protein 2. Brain Res 387, 271-280
15. Goedert $M$ and Jakes R (1990) Expression of separate isoforms of human tau protein: correlation with the tau pattern in brain and effects on tubulin polymerization. EMBO J 9, 4225-4230

16. Brandt R, Leger J and Lee G (1995) Interaction of tau with the neural plasma membrane mediated by tau's amino-terminal projection domain. J Cell Biol 131, 1327-1340

17. Chen J, Kanai Y, Cowan NJ and Hirokawa N (1992) Projection domains of MAP2 and tau determine spacings between microtubules in dendrites and axons. Nature 360, 674-677

18. Lee G, Neve RL and Kosik KS (1989) The microtubule binding domain of tau protein. Neuron 2, 1615-1624

19. Feinstein SC and Wilson L (2005) Inability of tau to properly regulate neuronal microtubule dynamics: a loss-of-function mechanism by which tau might mediate neuronal cell death. Biochim Biophys Acta 1739, 268-279

20. Goode BL, Chau M, Denis PE and Feinstein SC (2000) Structural and functional differences between 3-repeat and 4-repeat tau isoforms. Implications for normal tau function and the onset of neurodegenetative disease. J Biol Chem 275, 38182-38189

21. Adams SJ, DeTure MA, McBride M, Dickson DW and Petrucelli L (2010) Three repeat isoforms of tau inhibit assembly of four repeat tau filaments. PLoS One 5, e10810

22. Panda D, Samuel JC, Massie M, Feinstein SC and Wilson L (2003) Differential regulation of microtubule dynamics by three- and four-repeat tau: implications for the onset of neurodegenerative disease. Proc Natl Acad Sci U S A 100, 9548-9553

23. Stoothoff W, Jones PB, Spires-Jones TL et al (2009) Differential effect of three-repeat and four-repeat tau on mitochondrial axonal transport. J Neurochem 111, 417-427

24. Goedert M, Spillantini MG, Potier MC, Ulrich J and Crowther RA (1989) Cloning and sequencing of the cDNA encoding an isoform of microtubule-associated protein tau containing four tandem repeats: differential expression of tau protein mRNAs in human brain. EMBO J 8, 393-399

25. Hof PR, Bouras C, Perl DP and Morrison JH (1994) Quantitative neuropathologic analysis of Pick's disease cases: cortical distribution of Pick bodies and coexistence with Alzheimer's disease. Acta Neuropathol 87, 115-124

26. Caillet-Boudin ML, Buee L, Sergeant $N$ and Lefebvre $B$ (2015) Regulation of human MAPT gene expression. Mol Neurodegener 10, 28

27. Trabzuni D, Wray S, Vandrovcova J et al (2012) MAPT expression and splicing is differentially regulated by brain region: relation to genotype and implication for tauopathies. Hum Mol Genet 21, 4094-4103

28. Boutajangout A, Boom A, Leroy K and Brion JP (2004) Expression of tau mRNA and soluble tau isoforms in affected and non-affected brain areas in Alzheimer's disease. FEBS Lett 576, 183-189

29. Derisbourg M, Leghay C, Chiappetta G et al (2015) Role of the Tau $\mathrm{N}$-terminal region in microtubule stabilization revealed by new endogenous truncated forms. Sci Rep 5 , 9659 
30. Zhong Q, Congdon EE, Nagaraja HN and Kuret J (2012) Tau isoform composition influences rate and extent of filament formation. J Biol Chem 287, 20711-20719

31. Liu C, Song X, Nisbet R and Götz J (2016) Co-immunoprecipitation with tau isoform-specific antibodies reveals distinct protein interactions, and highlights a putative role for $2 \mathrm{~N}$ tau in disease. J Biol Chem 291, 8173-8188

32. Will CL and Lührmann R (2011) Spliceosome structure and function. Cold Spring Harb Perspect Biol 3, a003707

33. Qian W and Liu F (2014) Regulation of alternative splicing of tau exon 10. Neurosci Bull 30, 367-377

34. Kar A, Havlioglu N, Tarn WY and Wu JY (2006) RBM4 interacts with an intronic element and stimulates tau exon 10 inclusion. J Biol Chem 281, 24479-24488

35. Jiang Z, Tang H, Havlioglu N et al (2003) Mutations in tau gene exon 10 associated with FTDP-17 alter the activity of an exonic splicing enhancer to interact with Tra2 beta. J Biol Chem 278, 18997-19007

36. Kar A, Fushimi K, Zhou X et al (2011) RNA helicase p68 (DDX5) regulates tau exon 10 splicing by modulating a stem-loop structure at the 5' splice site. Mol Cell Biol 31, 1812-1821

37. Wang Y, Gao L, Tse SW and Andreadis A (2010) Heterogeneous nuclear ribonucleoprotein E3 modestly activates splicing of tau exon 10 via its proximal downstream intron, a hotspot for frontotemporal dementia mutations. Gene 451, 23-31

38. Broderick J, Wang J and Andreadis A (2004) Heterogeneous nuclear ribonucleoprotein E2 binds to tau exon 10 and moderately activates its splicing. Gene 331, 107-114

39. Dhaenens CM, Tran H, Frandemiche ML et al (2011) Mis-splicing of Tau exon 10 in myotonic dystrophy type 1 is reproduced by overexpression of CELF2 but not by MBNL1 silencing. Biochim Biophys Acta 1812, 732-742

40. Chapple JP, Anthony K, Martin TR, Dev A, Cooper TA and Gallo JM (2007) Expression, localization and tau exon 10 splicing activity of the brain RNA-binding protein TNRC4. Hum Mol Genet 16, 2760-2769

41. Smith PY, Delay C, Girard J et al (2011) MicroRNA-132 loss is associated with tau exon 10 inclusion in progressive supranuclear palsy. Hum Mol Genet 20, 4016-4024

42. Chen C, Jin N, Qian W et al (2014) Cyclic AMPdependent protein kinase enhances SC35-promoted Tau exon 10 inclusion. Mol Neurobiol 49, 615-624

43. Gu J, Shi J, Wu S et al (2012) Cyclic AMP-dependent protein kinase regulates 9G8-mediated alternative splicing of tau exon 10. FEBS Lett 586, 2239-2244

44. Jin N, Yin X, Gu J et al (2015) Truncation and Activation of Dual Specificity Tyrosine Phosphorylation-regulated Kinase $1 \mathrm{~A}$ by Calpain I: A MOLECULAR MECHANISM LINKED TO TAU PATHOLOGY IN ALZHEIMER DISEASE. J Biol Chem 290, 15219-15237

45. Ding S, Shi J, Qian W et al (2012) Regulation of alternative splicing of tau exon 10 by $9 \mathrm{G} 8$ and Dyrk1A. Neurobiol Aging 33, 1389-1399

46. Qian W, Liang H, Shi J et al (2011) Regulation of the alternative splicing of tau exon 10 by SC35 and Dyrk1A. Nucleic Acids Res 39, 6161-6171
47. Shi J, Zhang T, Zhou C et al (2008) Increased dosage of Dyrk1A alters alternative splicing factor (ASF)-regulated alternative splicing of tau in Down syndrome. J Biol Chem 283, 28660-28669

48. Chen KL, Yuan RY, Hu CJ and Hsu CY (2010) Amyloidbeta peptide alteration of tau exon-10 splicing via the GSK3beta-SC35 pathway. Neurobiol Dis 40, 378-385

49. Lev Maor G, Yearim A and Ast G (2015) The alternative role of DNA methylation in splicing regulation. Trends Genet 31, 274-280

50. Caffrey TM, Joachim C and Wade-Martins R (2008) Haplotype-specific expression of the $\mathrm{N}$-terminal exons 2 and 3 at the human MAPT locus. Neurobiol Aging 29, 1923-1929

51. Caffrey TM and Wade-Martins R (2007) Functional MAPT haplotypes: bridging the gap between genotype and neuropathology. Neurobiol Dis 27, 1-10

52. Pittman AM, Myers AJ, Abou-Sleiman P et al (2005) Linkage disequilibrium fine mapping and haplotype association analysis of the tau gene in progressive supranuclear palsy and corticobasal degeneration. J Med Genet 42, 837-846

53. McCarthy A, Lonergan R, Olszewska DA et al (2015) Closing the tau loop: the missing tau mutation. Brain 138, 3100-3109

54. Malkani R, D'Souza I, Gwinn-Hardy K, Schellenberg GD, Hardy J and Momeni P (2006) A MAPT mutation in a regulatory element upstream of exon 10 causes frontotemporal dementia. Neurobiol Dis 22, 401-403

55. Kowalska A, Hasegawa M, Miyamoto K et al (2002) A novel mutation at position +11 in the intron following exon 10 of the tau gene in FTDP-17. J Appl Genet 43, 535-543

56. Yasuda M, Takamatsu J, D'Souza I et al (2000) A novel mutation at position +12 in the intron following exon 10 of the tau gene in familial frontotemporal dementia (FTD-Kumamoto). Ann Neurol 47, 422-429

57. Hutton M, Lendon CL, Rizzu P et al (1998) Association of missense and 5 '-splice-site mutations in tau with the inherited dementia FTDP-17. Nature 393, 702-705

58. Spillantini MG, Murrell JR, Goedert M, Farlow MR, Klug A and Ghetti B (1998) Mutation in the tau gene in familial multiple system tauopathy with presenile dementia. Proc Natl Acad Sci U S A 95, 7737-7741

59. Anfossi M, Vuono R, Maletta R et al (2011) Compound heterozygosity of 2 novel MAPT mutations in frontotemporal dementia. Neurobiol Aging 32, 757.e1-757.e11

60. Stanford PM, Shepherd CE, Halliday GM et al (2003) Mutations in the tau gene that cause an increase in three repeat tau and frontotemporal dementia. Brain 126, 814-826

61. Stanford PM, Halliday GM, Brooks WS et al (2000) Progressive supranuclear palsy pathology caused by a novel silent mutation in exon 10 of the tau gene: expansion of the disease phenotype caused by tau gene mutations. Brain 123, 880-893

62. Spillantini MG, Yoshida H, Rizzini $C$ et al (2000) A novel tau mutation ( $\mathrm{N} 296 \mathrm{~N})$ in familial dementia with swollen achromatic neurons and corticobasal inclusion bodies. Ann Neurol 48, 939-943 
63. D'Souza I, Poorkaj P, Hong M et al (1999) Missense and silent tau gene mutations cause frontotemporal dementia with parkinsonism-chromosome 17 type, by affecting multiple alternative RNA splicing regulatory elements. Proc Natl Acad Sci U S A 96, 5598-5603

64. Umeda T, Yamashita T, Kimura T et al (2013) Neurodegenerative disorder FTDP-17-related tau intron $10+16 \mathrm{C}$ $\rightarrow$ T mutation increases tau exon 10 splicing and causes tauopathy in transgenic mice. Am J Pathol 183, 211-225

65. Ghetti B, Oblak AL, Boeve BF, Johnson KA, Dickerson BC and Goedert $M$ (2015) Invited review: Frontotemporal dementia caused by microtubule-associated protein tau gene (MAPT) mutations: a chameleon for neuropathology and neuroimaging. Neuropathol Appl Neurobiol 41, 24-46

66. Hayashi S, Toyoshima Y, Hasegawa M et al (2002) Late-onset frontotemporal dementia with a novel exon 1 (Arg5His) tau gene mutation. Ann Neurol 51, 525-530

67. Poorkaj P, Muma NA, Zhukareva V et al (2002) An R5L tau mutation in a subject with a progressive supranuclear palsy phenotype. Ann Neurol 52, 511-516

68. Grover A, England E, Baker $M$ et al (2003) A novel tau mutation in exon $9(1260 \mathrm{~V})$ causes a four-repeat tauopathy. Exp Neurol 184, 131-140

69. Ros R, Thobois S, Streichenberger N et al (2005) A new mutation of the tau gene, G303V, in early-onset familial progressive supranuclear palsy. Arch Neurol 62, 1444-1450

70. Tacik P, DeTure M, Lin WL et al (2015) A novel tau mutation, p.K317N , causes globular glial tauopathy. Acta Neuropathol 130, 199-214

71. Lippa CF, Zhukareva V, Kawarai T et al (2000) Frontotemporal dementia with novel tau pathology and a Glu342Val tau mutation. Ann Neurol 48, 850-858

72. de Silva R, Lashley T, Strand C et al (2006) An immunohistochemical study of cases of sporadic and inherited frontotemporal lobar degeneration using 3R-and 4R-specific tau monoclonal antibodies. Acta Neuropathol $111,329-340$

73. Baker M, Litvan I, Houlden $\mathrm{H}$ et al (1999) Association of an extended haplotype in the tau gene with progressive supranuclear palsy. Hum Mol Genet 8, 711-715

74. Pittman AM, Fung HC and de Silva R (2006) Untangling the tau gene association with neurodegenerative disorders. Hum Mol Genet 15 Spec No 2, R188-195

75. Rademakers R, Melquist $S$, Cruts $M$ et al (2005) High-density SNP haplotyping suggests altered regulation of tau gene expression in progressive supranuclear palsy. Hum Mol Genet 14, 3281-3292

76. Houlden H, Baker M, Morris HR et al (2001) Corticobasal degeneration and progressive supranuclear palsy share a common tau haplotype. Neurology 56, 1702-1706

77. Li Y, Chen JA, Sears RL et al (2014) An epigenetic signature in peripheral blood associated with the haplotype on $17 \mathrm{q} 21.31$, a risk factor for neurodegenerative tauopathy. PLoS Genet 10, e1004211

78. Sobrido MJ, Miller BL, Havlioglu N et al (2003) Novel tau polymorphisms, tau haplotypes, and splicing in familial and sporadic frontotemporal dementia. Arch Neurol 60, 698-702
79. Bruch J, Xu H, De Andrade A and Hoglinger G (2014) Mitochondrial complex 1 inhibition increases 4-repeat isoform tau by SRSF2 upregulation. PLoS One 9, e113070

80. McMillan P, Korvatska E, Poorkaj P et al (2008) Tau isoform regulation is region- and cell-specific in mouse brain. J Comp Neurol 511, 788-803

81. Majounie E, Cross W, Newsway V et al (2013) Variation in tau isoform expression in different brain regions and disease states. Neurobiol Aging 34, 1922.e7-1922.e12

82. Fernandez-Nogales M, Cabrera JR, Santos-Galindo $M$ et al (2014) Huntington's disease is a four-repeat tauopathy with tau nuclear rods. Nat Med 20, 881-885

83. Jiang $H$, Mankodi A, Swanson MS, Moxley RT and Thornton CA (2004) Myotonic dystrophy type 1 is associated with nuclear foci of mutant RNA, sequestration of muscleblind proteins and deregulated alternative splicing in neurons. Hum Mol Genet 13, 3079-3088

84. Seznec H, Agbulut O, Sergeant N et al (2001) Mice transgenic for the human myotonic dystrophy region with expanded CTG repeats display muscular and brain abnormalities. Hum Mol Genet 10, 2717-2726

85. Brook JD, McCurrach ME, Harley HG et al (1992) Molecular basis of myotonic dystrophy: expansion of a trinucleotide (CTG) repeat at the $3^{\prime}$ end of a transcript encoding a protein kinase family member. Cell 68, 799-808

86. The Huntington's Disease Collaborative Research Group (1993) A novel gene containing a trinucleotide repeat that is expanded and unstable on Huntington's disease chromosomes. Cell 72, 971-983

87. Mykowska A, Sobczak K, Wojciechowska M, Kozlowski P and Krzyzosiak WJ (2011) CAG repeats mimic CUG repeats in the misregulation of alternative splicing. Nucleic Acids Res 39, 8938-8951

88. Deng HX, Zhai H, Bigio EH et al (2010) FUSimmunoreactive inclusions are a common feature in sporadic and non-SOD1 familial amyotrophic lateral sclerosis. Ann Neurol 67, 739-748

89. Neumann M, Sampathu DM, Kwong LK et al (2006) Ubiquitinated TDP-43 in frontotemporal lobar degeneration and amyotrophic lateral sclerosis. Science 314, 130-133

90. Gitcho MA, Bigio EH, Mishra M et al (2009) J. TARDBP 3'-UTR variant in autopsy-confirmed frontotemporal lobar degeneration with TDP-43 proteinopathy. Acta Neuropathol 118, 633-645

91. Kwiatowski TJ Jr, Bosco DA, LeClerc AL et al (2009) Mutations in the FUS/TLS gene on chromosome 16 cause familial amyotrophic lateral sclerosis. Science 323, 1205-1208

92. Buratti $E$, Dörk $T$, Zuccato $E$, Pagani $F$, Romano $M$, and Baralle FE (2001) Nuclear factor TDP-43 and SR proteins promote in vitro and in vivo CFTR exon 9 skipping. EMBO J 20, 1774-1784

93. Yang L, Embree LJ, Hickstein DD (2000) TLS-ERG leukemia fusion protein inhibits RNA splicing mediated by serine-arginine proteins. Mol Cell Biol 20, 3345-3354

94. Orozco D, Tahirovic S, Rentzsch K, Schwenk BM, Haass $C$ and Edbauer D (2012) Loss of fused in sarcoma (FUS) promotes pathological Tau splicing. EMBO Rep 13, 


\section{9-764}

95. Tollervey JR, Curk T, Rogelj B et al (2011) Characterizing the RNA targets and position-dependent splicing regulation by TDP-43. Nat Neurosci 14, 452-458

96. Highley JR, Kirby J, Jansweijer JA et al (2014) Loss of nuclear TDP-43 in amyotrophic lateral sclerosis (ALS) causes altered expression of splicing machinery and widespread dysregulation of RNA splicing in motor neurones. Neuropathol Appl Neurobiol 40, 670-685

97. Liu Y, Rodriguez L and Wolfe MS (2014) Templatedirected synthesis of a small molecule-antisense conjugate targeting an mRNA structure. Bioorg Chem 54, 7-11

98. Kalbfuss B, Mabon SA and Misteli T (2001) Correction of alternative splicing of tau in frontotemporal dementia and parkinsonism linked to chromosome 17. J Biol Chem 276, 42986-42993.

99. Rodriguez-Martin T, Anthony K, Garcia-Blanco MA Mansfield SG, Anderton BH and Gallo J-M (2009) Correction of tau mis-splicing caused by FTDP-17 MAPT mutations by spliceosome-mediated RNA trans-splicing. Hum Mol Genet 18, 3266-3273 